\title{
Silicon/Spent Coffee Waste-derived Carbon Composite as an Efficient Anode for Li-ion Batteries
}

\author{
Nulu Venugopal \\ Department of Nanoscience and Engineering, Center for Nano Manufacturing, Inje University, 197 \\ Inje-ro, Gimhae, Gyeongnam-do 50834, Republic of Korea \\ E-mail: venungopal@inje.ac.kr; venungopal@gmail.com
}

doi: $10.20964 / 2021.08 .05$

Received: 23 March 2021 / Accepted: 18 May 2021 / Published: 30 June 2021

Silicon anodes are the most investigated materials for Li-ion batteries (LIBs) owing to their high theoretical capacity and low working potential. However, significant volume changes and low conductivity hinder their practical applications. The addition of carbon and the formation of a silicon/carbon composite are established paths for improving the structural stability and conductivity of silicon anodes. In this study, spent coffee waste (SCW) was chosen as an eco-friendly and cost-effective carbon source for fabricating a composite with silicon. The prepared Si and SCW-derived activated carbon (SCWAC) composite was studied as an anode for Li-ion batteries. The composite exhibited improved electrochemical performance compared to bare silicon nanoparticles. The noticeable improvement could be attributed to the structural stability and conductivity provided by the SCWAC matrix. The proposed composite delivered a discharge capacity of $1122 \mathrm{mAh} \mathrm{g}^{-1}$ after 100 cycles at a current density of $200 \mathrm{~mA} \mathrm{~g}$. The composite also showed better $\mathrm{Li}^{+}$diffusion properties, which enhanced the $\mathrm{Li}^{+}$-ion storage capability. This work contributes to the development of eco-environmental batteries using low-cost materials, as a promising solution to address increasing energy storage demands.

Keywords: coffee waste-derived carbon, silicon-carbon composite, anode material, li-ion diffusion, liion batteries

\section{$\underline{\text { FULL TEXT }}$}

(C) 2021 The Authors. Published by ESG (www.electrochemsci.org). This article is an open access article distributed under the terms and conditions of the Creative Commons Attribution license (http://creativecommons.org/licenses/by/4.0/). 